\title{
ARTICLE
}

\section{Impact of Autonomous Vehicles on Parking Spaces}

\author{
Nikhil Sai Yekollu $^{1^{*}}$ Kasim A Korkmaz $^{2}$ \\ 1. Construction Management, Eastern Michigan University, Ypsilanti, MI, United States \\ 2. School of Visual and Built Environment, Eastern Michigan University, United States
}

\begin{tabular}{|c|c|}
\hline ARTICLE INFO & ABSTRACT \\
\hline Article history & \multirow{10}{*}{$\begin{array}{l}\text { The United States has an enormous supply of parking and with the appro- } \\
\text { priation of Autonomous vehicles, the interest for these spaces could change } \\
\text { drastically. Parking is among the most pervasive land utilizes involving up } \\
\text { to } 31 \% \text { of urban territory. With completely automated vehicles expected } \\
\text { on the customer advertise by } 2020 \text {, the } \$ 30 \text { billion leaving industry will } \\
\text { encounter gigantic changes as autos develop. The purpose of this paper is } \\
\text { to analyse how the parking and garage spaces can be utilized after the im- } \\
\text { plementation of automated vehicles in every household. Analysis has been } \\
\text { conducted about different households in Ypsilanti Township using Zillow } \\
\text { application which includes the address, area of the house, parking area and } \\
\text { year in which it is built. Results are based on the analysis conducted on the } \\
\text { houses and the impact of the autonomous vehicles on their parking space. }\end{array}$} \\
\hline Received: 26 April 2019 & \\
\hline Accepted: 29 April 2019 & \\
\hline Published Online: 30 April 2020 & \\
\hline Keywords: & \\
\hline Structure & \\
\hline Garage & \\
\hline Uarage & \\
\hline Household & \\
\hline Transit & \\
\hline
\end{tabular}

\section{Introduction}

$\mathrm{A}$ utonomous vehicles have for quite some time been in the domain, of sci-fi, anyway recent progress implies that these driver-less autos will be on our avenues in the generally not so distant future. There is solid challenge between more current innovation organizations, (for example, Google, Uber and Tesla) and set up vehicle organizations, (for example, Mercedes Benz, General Motors, Nissan and numerous others). Some have been taking a shot at automated vehicles for quite a long time, and there are many working models and preliminary projects. Clearly there are still parts of the driver-less vehicle that still should be refined, and there are numerous lawful, obligation, specialized and social issues that must be survived. However, as far as transport arranging into the future, automated vehicles ought to be considered, as they are probably going to have significant impacts which affect travel conduct and road network operations.
The question of how rapidly Autonomous vehicles will set up advertise strength is troublesome, and a scope of feelings have been advertised. Various vehicle organizations have anticipated the completely automated vehicles will be available inside the following 5-10 years. How rapidly the market will take up these vehicles is obscure, and most projections are finished by taking a glance at the development pace of past advances. In 2012, a board of IEEE individuals anticipated that $75 \%$ of the fleet would be autonomous by $2040^{[1]}$. The Victoria Transport Policy Institute predicts a slower take-up - with the $75 \%$ market being accomplished by $2060^{[2]}$. This depended on correlations with other vehicle advancements, for example, programmed transmission, on-board route and hybrid vehicles, all of which took a very long while to arrive at huge market catch.

\section{Literature Review}

The first vehicle was an impetus for a significant part of

*Corresponding Author:

Nikhil Sai Yekollu,

Construction Management, Eastern Michigan University, Ypsilanti, MI, United States;

Email:nyekollu@emich.edu 
the monetary development and the appropriation of individuals in the US over the twentieth century ${ }^{[3]}$. It changed the state of urban communities as managers and family units were progressively prepared as they continued looking for lower leases and moved further from the middle. Area didn't overwhelm urban improvement similarly when one could travel further, quicker and for less cash. Area turned out to be less about the prompt physical surroundings estimated in miles and progressively about the portability estimated in minutes. We started to adjust the structure and size of our streets, homes, and organizations to help our reliance on the vehicle. Streets got straighter and more extensive; homes increased with two-vehicle carports; and least leaving benchmarks expanded the advancement of land in our urban communities. The change of undeveloped to created land expanded at a rate $40 \%$ quicker than the populace development since $1950^{[4]}$. Expanded requirement for space is because of our craving for the vehicle.

\subsection{History of Parking}

The most punctual parking spots were initially curb side. The increase in individual vehicle ownership, implied a decrease in direct space crosswise over avenues. In 1923, Columbus Ohio turned into the first American city to arrange parking guideline as a major aspect of a zoning mandate for multi-family ${ }^{[5]}$. In 1926 , an across the nation overview of downtown vendors recorded traffic blockage as their most significant issue ${ }^{[6,7]}$. Urban communities started to require and classify off-road parking standards and point of confinement on-road parking. The main parking meter for on-road parking was introduced in Oklahoma City in 1935. This pushed private landowners to start to create reason-manufactured parking structures as remain solitary structures or as a major aspect of bigger business advancements. By 1946 a review of 76 US urban areas found that solitary 17 percent of regions had parking ordinances. Within 5 years, 71 percent had or were receiving them ${ }^{[7]}$. By 1949, 185 urban communities had embraced least stopping guidelines. By the 1970s, $95 \%$ of urban areas within excess of 25,000 occupants had received stopping necessities ${ }^{[8]}$. Minimum parking necessities joined with escalating car ownership has seen an enormous designation of fabricated space to parking.

\subsection{Parking Estimates}

In 2010, San Francisco turned into the first American city to endeavour an enumeration of its parking yet restricted the examination to on-road spaces as it were. Urban communities require various quantities of parking spots per every grouping of land use, yet few have a definite information on the total parking supply ${ }^{[9]}$. Normal parking proportions fall between 3 to 4 spaces for every 1,000 sf of building floor zone ${ }^{[10]}$. The proportion may appear to be low from the start, however least parking prerequisites frequently require all the area of (surface) parking than building territory that it applies to. The fundamental parking measurements of 9'x18' stall and a 24' width drive path imply that $1000 \mathrm{sf}$ of building requires more than $1,080 \mathrm{sf}$ of parking area.

Parking proportions are frequently set as essentials and scale with the size of the structure ${ }^{[10]}$. It is presently evaluated between 3.3 parking spots per vehicle ${ }^{[11]}$. This gauge fluctuates broadly as it is hard to discover the parking in private regions like single family home carports, in garages, or even along roads that are not appropriately stamped or estimated. Chester et al. (2015) gauges the quantity of parking spots in the US is between 800 million to 2 billion in temporal and spatial examination of Los Angeles. At a normal of 350 square feet for each parking space, that is generally the size of Connecticut as a traditionalist gauge, or the province of West Virginia on the upper end.

\subsection{Impact of Autonomous vehicles on Mobility}

Autonomous vehicles will turn out to be exceptionally appealing contrasted with built up movement modes at some point in time and are regarded as a disruptive force in the transport market ${ }^{[12]}$. On one hand, this will be pushed by profoundly aggressive costs ${ }^{[11]}$ and on the other hand through increased comfort and the possibility to pursue useful activities while voyaging ${ }^{[13]}$. It is normal that different types of self-sufficient voyaging will join towards an all-inclusive travel method of on-request independent vehicle services ${ }^{[14]}$, which can be viewed as a totally new method of transport ${ }^{[15]}$.

An expansion in trafic limit is required to happen considering two or three different factors:

Associated AV's will make it feasible for vehicles to convey and along these lines decline the important separation for safe driving ${ }^{[16]}$. In like manner, having information about other vehicles intentions, accelerations and braking makes it possible to avoid the emergence of trafic-jams and suggest a much better trafic flow than is present today. One example being the intelligent control of intersections ${ }^{[17]}$.

Crashes today reduce the road capacity. Assuming AV's are much more-safe and reduce the number of crashes significantly, this will also allow for a higher average capacity in the trafic network. Bertoncello and Wee (2015) expects a reduction of trafic crashes by $90 \%{ }^{[18]}$. Also, Fagnant and Kockelman (2015) suggest that a penetration 
level of $10 \%$ AV's would lead to half the number of crashes today, while a level of $90 \%$ they would remove $90 \%$ of mishaps ${ }^{[19]}$.

Are developed infrastructure, aimed at supporting a trafic system mainly consisting of AV's will have the potential to create huge gains in capacity by making use of several AV advantages, such as the ability to autonomously drive to parking spaces or the possibility to optimally dispatch vehicles according to the current demand at a certain time of the day. Those infrastructure changes will be described in a later chapter.

\subsection{Impact of Autonomous Vehicles on Infrastruc- ture}

Particularly in profoundly blocked zones, parking spots are relied upon to disappear, either to make space for additional roads or to be converted to a completely different use. This is conceivable since AV's don't have to remain at the client goal. It is possible that they can come back to deliberately situated versatility hubs or wander through the city. All things considered, Zhang etal. (2015) estimate a decrease of $90 \%$ in parking spots for AV clients at low all out offers in the urban zone. Since this decrease incites an expansion in vehicle kilometres voyaged every day (VKT), it is contended that this decrease can be incompletely sacrificed against giving a lot of parking spot. Despite that, extended spaces for getting and dropping off clients are required. This is particularly valid for enormous occasion venues, where high quantities of explorers are normal at specific times.

The associated city will rise, overseeing trafic information on the fly and disseminating data to consider the most ideal flow. This incorporates the usage of keen trafic lights, which respond to the present interest on the streets. Moreover, robotized intersections are discussed where no trafic lights are required by any stretch of the imagination, since AV's can consult on their own, who will cross first ${ }^{[17]}$. Then, however, it is necessary to give pedestrians safe ways of interacting with such new trafic management openings. This leads to inquire about towards requesting a human-centric advancement of cities, offering equivalent open doors for each participant; Late viewpoints on the effect of self-sufficient vehicles ${ }^{[20]}$. The changes required in the parking area and the analysis will be discussed in later sections.

\section{Methodology}

Information about few houses in Ypsilanti Township has been collected using Zillow application. The application describes everything about the houses including the minor details. For the purpose of the paper, only some of the houses for sale are selected among all the houses in the town- ship. Comparison is carried out on the different houses and their parking structures. Exhibit 1 illustrates the application which is used to get the information about the households and Exhibit 2 describes the details of the households.

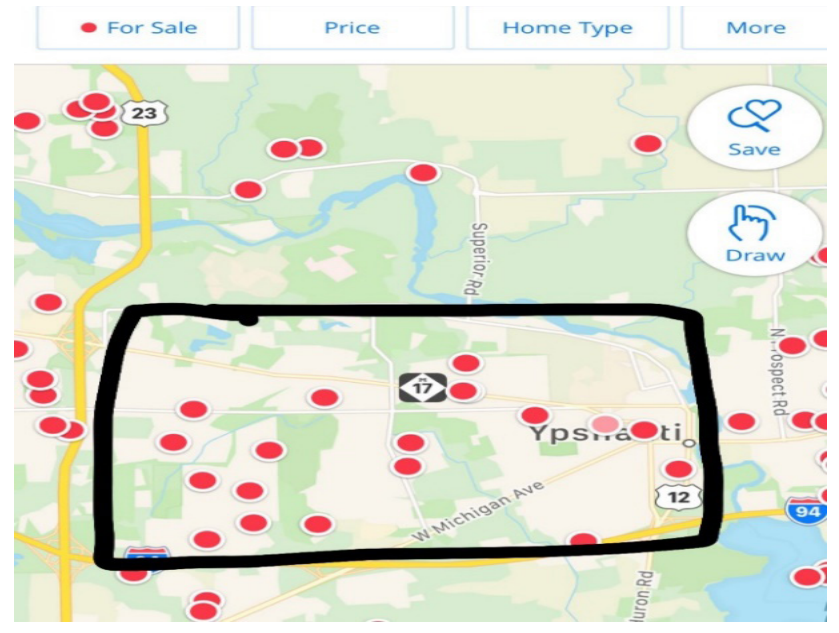

Exhibit 1. Zillow application illustrating the households selected

\begin{tabular}{|c|c|c|c|}
\hline HOUSE ADDRESS & $\begin{array}{c}\text { AREA OF THE } \\
\text { HOUSE (SQ. FT) }\end{array}$ & $\begin{array}{c}\text { PARKING AREA } \\
\text { (SQ. FT) }\end{array}$ & $\begin{array}{c}\text { BUILT IN } \\
\text { YEAR }\end{array}$ \\
\hline $\begin{array}{c}\text { 3315 oak Drive, Ypsi- } \\
\text { lanti }\end{array}$ & 2205 & 13068 (2 spaces) & 1976 \\
\hline $\begin{array}{c}\text { 3731 Hillside Drive, } \\
\text { Ypsilanti }\end{array}$ & 1232 & 13068 (4 spaces) & 1972 \\
\hline $\begin{array}{c}\text { 3855 Palisades boule- } \\
\text { vard, Ypsilanti }\end{array}$ & 1985 & $11325.6(2$ spaces $)$ & 1995 \\
\hline $\begin{array}{c}\text { 3999 Palisades boule- } \\
\text { vard, Ypsilanti }\end{array}$ & 1968 & 13939.2 (2 spaces) & 1994 \\
\hline $\begin{array}{c}\text { 3848 Golf-side road, } \\
\text { Ypsilanti }\end{array}$ & 1222 & $11761.2(2$ spaces $)$ & 1971 \\
\hline $\begin{array}{c}\text { 2454 Midvale street, } \\
\text { Ypsilanti }\end{array}$ & 2070 & $14374.8(2$ spaces $)$ & 1963 \\
\hline $\begin{array}{c}\text { 2420 Merrill street, } \\
\text { Ypsilanti }\end{array}$ & 1399 & $14374.8(2$ spaces $)$ & 1964 \\
\hline $\begin{array}{c}\text { 2333 Draper Avenue, } \\
\text { Ypsilanti }\end{array}$ & 1803 & $11325.6(4$ spaces $)$ & 1976 \\
\hline $\begin{array}{c}\text { 4110 Silverleaf Drive, } \\
\text { Ypsilanti }\end{array}$ & 2620 & 13068 (4spaces) & 1995 \\
\hline $\begin{array}{c}\text { 2525 Eastlawn street, } \\
\text { Ypsilanti }\end{array}$ & 1555 & 10454 (4spaces) & 1984 \\
\hline
\end{tabular}

Exhibit 2. Illustrating the details of the households

House 1: 3315 Oak Drive, Ypsilanti: The total area of the house is 2205 square feet and a parking lot of 13068 square feet which is utilized by 2 parking spaces. As per the fundamentals, an area of 350 square feet is enough for a single parking space. So, an area of 700 square feet is enough for 2 parking spaces. For convenient mobilization the total can be sum up to approximately 1000 square feet. However, there will be no change in the structure of autonomous vehicles, they can utilize the same space for their parking. Autonomous vehicles prefer separate parking spaces other than the regular garage space, but it depends on the location. Exhibit 3 illustrates the parking space for the mentioned house. 


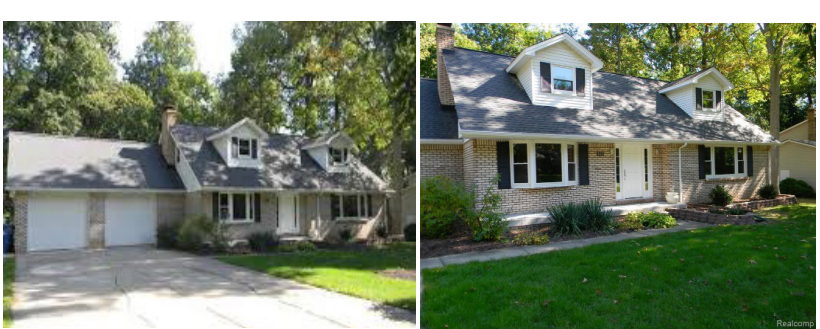

Exhibit 3. Images of 3315 Oak Drive, Ypsilanti

Note: (URL1, 2020, https://images.app.goo.gl/cNnzWTsDkx8P6Jty8 )

House 2: 3731 Hillside Drive, Ypsilanti: The total area of the house is 1232 square feet and a parking lot of 13068 square feet which is utilized by 4 parking spaces. Dimensions of $9^{\prime} * 18^{\prime}$ and $24^{\prime}$ 'width are the standards of parking which imply that 1000 square feet of building requires a minimum of 1080 square feet for parking area. By calculation, an area of 1500 square feet is enough for 4 parking spaces and the rest of the area can be utilized for other purposes. Exhibit 4 illustrates the parking space for the mentioned house.

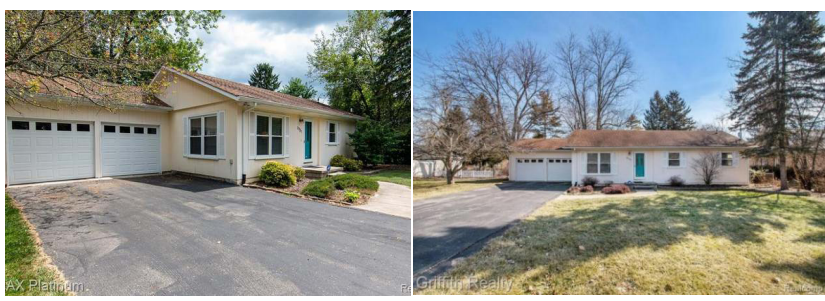

Exhibit 4. Images of 3731 Hillside Drive, Ypsilanti

Note: (URL2, 2020, https://images.app.goo.gl/dF4LoiakDafPHGAr8)

House 3: 3855 Palisades Boulevard, Ypsilanti: The total area of the house is 1985 square feet and a parking lot of 11324.6 square feet which is utilized by 2 parking space. A garage must have a minimum height of 8'2" and parking space width between 8'6" and 9'0" wide. So, as per the calculation Approximately 1000 square feet is enough for 2 parking spaces and rest of the area can be utilized for other purposes. Autonomous vehicles can use the same parking space, or they can prefer separate parking structures, it depends on the owner of the vehicle. Exhibit 5 illustrates the parking space for mentioned space.
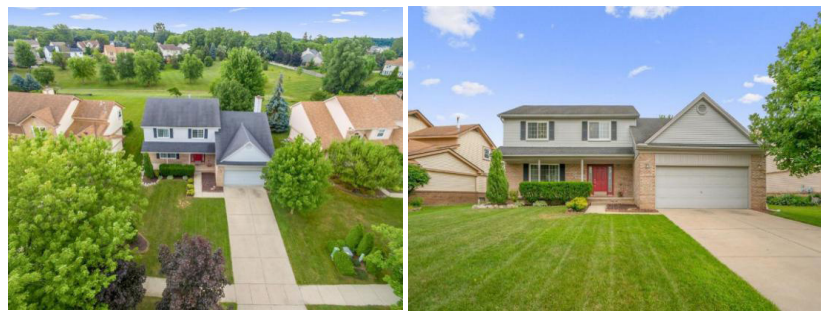

Exhibit 5. Images of 3855 Palisades Boulevard, Ypsilanti

Note: (URL3, 2020, https://images.app.goo.gl/PyaMU4ouR82Cfgto7)

House 4: 3999 Palisades Boulevard, Ypsilanti: The total area of the house is 1968 square feet and a parking lot of 13939.2 square feet which is utilized by 2 parking spaces. As per the fundamentals, an area of 350 square feet is enough for a single parking space. So, an area of 700 square feet is enough for 2 parking spaces. For convenient mobilization the total can be sum up to approximately 1000 square feet. However, there will be no change in the structure of autonomous vehicles, they can utilize the same space for their parking. Autonomous vehicles prefer separate parking spaces other than the regular garage space, but it depends on the location. Exhibit 6 illustrates the parking space for the mentioned house.
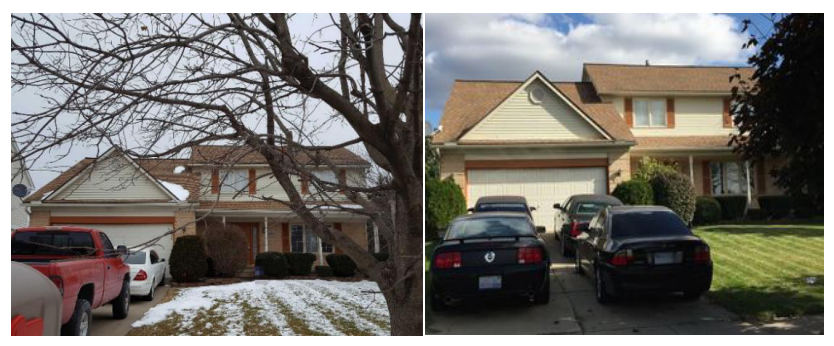

Exhibit 6. Images of 3999 Palisades Boulevard, Ypsilanti

Note: (URL4, 2020, https://images.app.goo.gl/7LWB6PaLKGr6y7hs5)

House 5: 3848 Golf-side road, Ypsilanti: The total area of the house is 1222 square feet and a parking lot of 11761.2 square feet which is utilized by 2 parking spaces. Dimensions of 9'*18' and 24' width are the standards of parking which imply that 1000 square feet of building requires a minimum of 1080 square feet for parking area. By calculation, an area of 1200 square feet is enough for 2 parking spaces and the rest of the area can be utilized for other purposes. Exhibit 7 illustrates the parking space for the mentioned house.
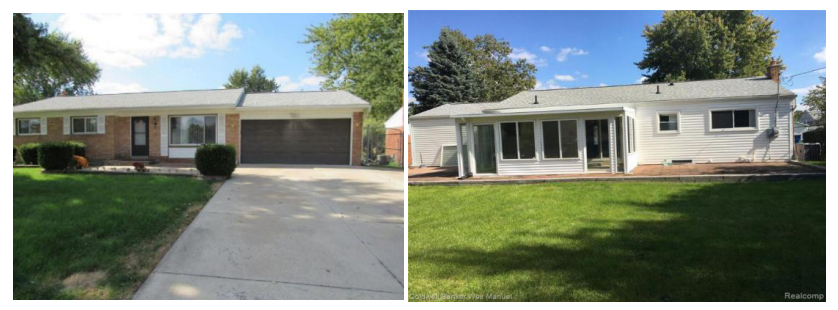

Exhibit 7. Images of 3848 Golf-Side Road, Ypsilanti

Note: (URL5, 2020, https://images.app.goo.gl/hqZEYU2M6JoehwwU8)

House 6: 2454 Midvale Street, Ypsilanti: The total area of the house is 2070 square feet and a parking lot of 14374.8 square feet which is utilized by 2 parking space. A garage must have a minimum height of 8 ' 2 " and parking space width between 8'6" and 9'0" wide. So, as per the calculation Approximately 1200 square feet is enough for 2 parking spaces and rest of the area can be utilized for other purposes. Autonomous vehicles can use the same parking space, or they can prefer separate parking structures, it depends on the owner of the vehicle. Exhibit 8 illustrates the parking space for mentioned space. 


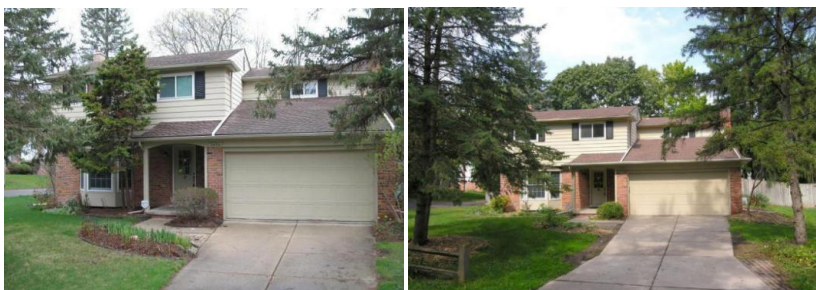

Exhibit 8. Images of 2454 Midvale street, Ypsilanti

Note: (URL6, 2020, https://images.app.goo.gl/CD88vbUxtzUeXuM37)

House 7: 2420 Merrill Street, Ypsilanti: The total area of the house is 1399 square feet and a parking lot of 14374.8 square feet which is utilized by 2 parking spaces. As per the fundamentals, an area of 350 square feet is enough for a single parking space. So, an area of 700 square feet is enough for 2 parking spaces. For convenient mobilization the total can be sum up to approximately 1200 square feet. However, there will be no change in the structure of autonomous vehicles, they can utilize the same space for their parking. Autonomous vehicles prefer separate parking spaces other than the regular garage space, but it depends on the location. Exhibit 9 illustrates the parking space for the mentioned house.
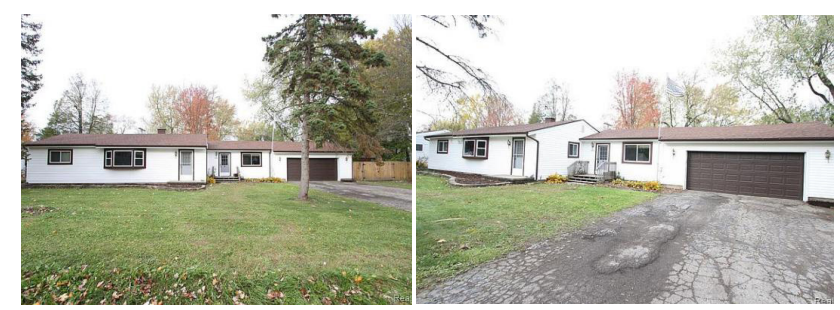

Exhibit 9. Images of 2420 Merrill Street, Ypsilanti

Note: (URL7, 2020, https://images.app.goo.gl/BNCiM8SoRwjq5ywu9)

House 8: 2333 Draper Avenue, Ypsilanti: The total area of the house is 1803 square feet and a parking lot of 11325.6 square feet which is utilized by 4 parking spaces. Dimensions of $9^{\prime} * 18^{\prime}$ and $24^{\prime}$ 'width are the standards of parking which imply that 1000 square feet of building requires a minimum of 1080 square feet for parking area. By calculation, an area of 1600 square feet is enough for 4 parking spaces and the rest of the area can be utilized for other purposes. Exhibit 10 illustrates the parking space for the mentioned house.
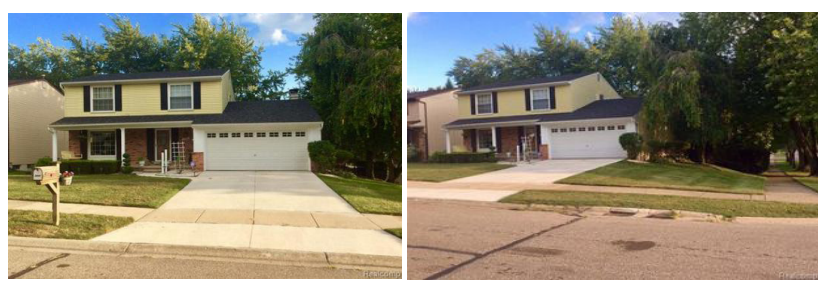

Exhibit 10. Images of 2333 Draper Avenue, Ypsilanti

Note: (URL8, 2020, https://images.app.goo.gl/sd2hjEhpaaexwLu69)
House 9: 4110 Silverleaf Drive, Ypsilanti: The total area of the house is 2620 square feet and a parking lot of 13068 square feet which is utilized by 4 parking space. A garage must have a minimum height of 8 '2" and parking space width between 8'6" and 9'0" wide. So, as per the calculation Approximately 1600 square feet is enough for 4 parking spaces and rest of the area can be utilized for other purposes. Autonomous vehicles can use the same parking space, or they can prefer separate parking structures, it depends on the owner of the vehicle. Exhibit 11 illustrates the parking space for mentioned space.
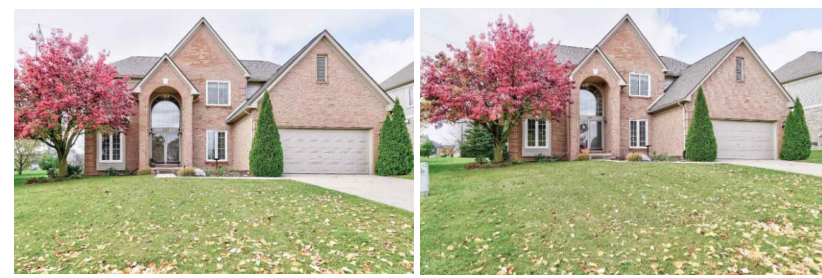

Exhibit 11. Images of 4110 Silverleaf Drive, Ypsilanti

Note: (URL9, 2020, https://images.app.goo.gl/XXHUty78jusuPaBV8 )

House 10: 2525 Eastlawn street, Ypsilanti: The total area of the house is 1555 square feet and a parking lot of 10454 square feet which is utilized by 4 parking spaces. Dimensions of $9^{\prime} * 18^{\prime}$ and 24 ' width are the standards of parking which imply that 1000 square feet of building requires a minimum of 1080 square feet for parking area. By calculation, an area of 1600 square feet is enough for 4 parking spaces and the rest of the area can be utilized for other purposes. Exhibit 12 illustrates the parking space for the mentioned house and Exhibit 13 illustrates the area distribution of the mentioned houses.

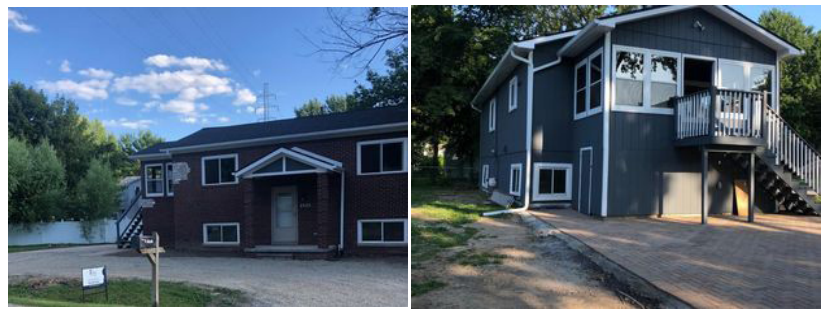

Exhibit 12. Images of 2525 Eastlawn Street, Ypsilanti

Note: (URL10, 2020, https://images.app.goo.gl/5xJRmcHaBuEtu6bs6)

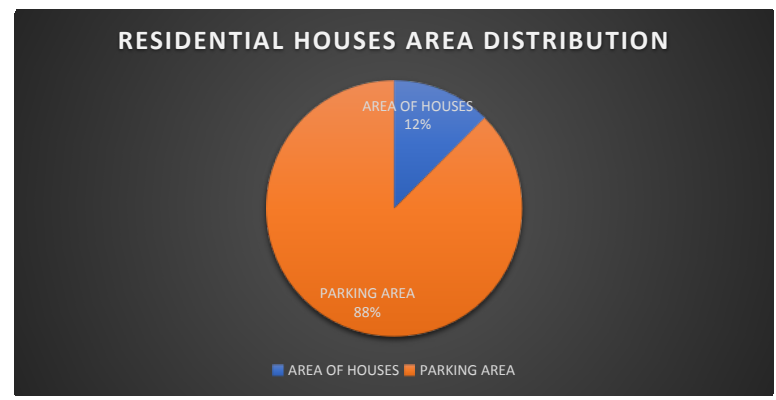

Exhibit 13. Illustration of Area distribution 
However, the parking area of the houses mentioned in exhibit 2 includes the garage space and the remaining lot. The above mentioned, houses have the garage spaces, so the autonomous vehicles can park in those spaces as there is not much change in that. In contrast, there are many houses in the Ypsilanti region without garage spaces or lots and therefore they must park their vehicles on the streets. If this is the scenario, then there is a need or separate parking structures for the autonomous vehicles to park. Exhibit 14 illustrates the houses without garage spaces.

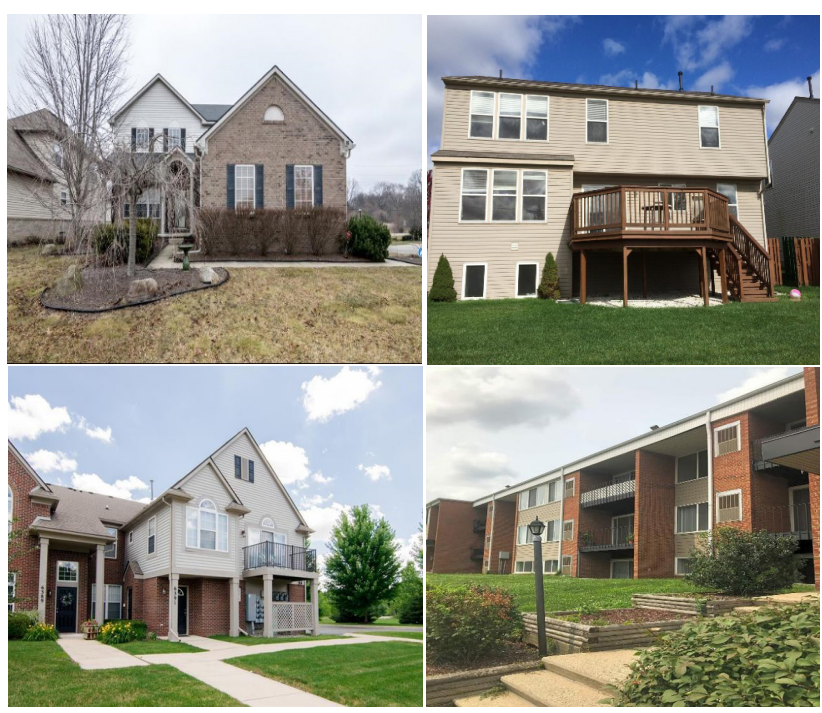

Exhibit 14. Images of houses without garages in Ypsilanti

Note: (URL11, 2020, https://images.app.goo.gl/HQ5CmYvqaEaCmKoy8)

\section{Discussion}

The present vehicles are either determined legitimately from home to the work, or the user needs to walk to the location of the vehicle toward the beginning of the journey and again from the leaving to the last destination. One effect of autonomous driving, in any case, will be that these distances before and after the journey will be made by the vehicle, not the driver. The driving robot will work the vehicle from its unique parking spot to the area of the proprietor/user and, subsequent to showing up at the destination, to an assigned parking spot.

In general, the normal changes in the zone required for home parking are small, although they vary as per kind of settlement structure. In private neighbourhoods of single-family houses, where parking spots are on a similar plot as the home, no progressions are expected. The accessible parking spot will just be occupied by an autonomous vehicle. In regions of higher density, for example, downtown areas, it might be expected that local parking zones or collective garages will show up or be created, as just right now autonomous vehicles be ensured to find a space in the neighbourhood-defined catchment zone. It is additionally expected here that sufficient parking limit will be given to permit vehicles to find a space securely and dependably. Exhibit 15 shows the autonomous parking system that is expected to have in future.

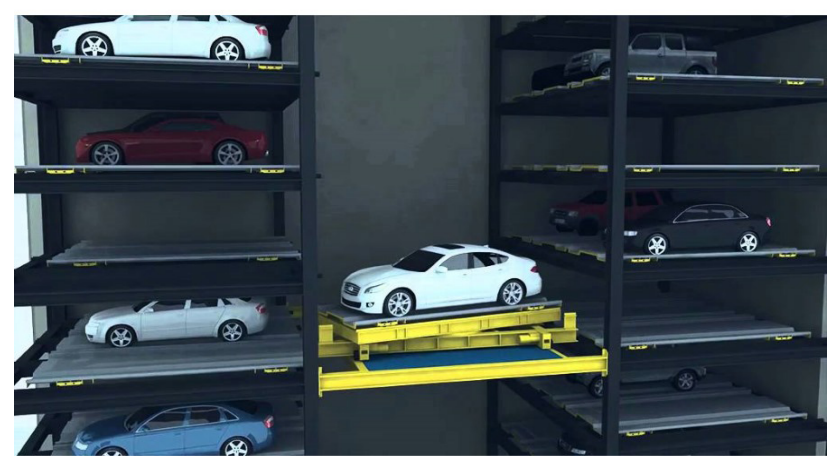

Exhibit 15. A model of Autonomous parking structure

The efficient utilization of space for parking is particularly appealing as far as expenses. Parking spots required for building advancements devour a great deal of space and represent a significant portion of the expenses of the entire venture, especially when the garage to be fabricated isn't at ground level. There have just been a few ventures testing parking in garages with autonomous vehicles. The driver hands the vehicle over at the garage entrance. The parking capacity is activated with a cell phone application. The vehicle gets the course information to the closest accessible space from a central garage computer by means of Wireless local area network (WLAN) and drives to it automatically. A programmed parking system as of now in presence may fill in for instance. All essential vehicle developments, aside from passage and exit into a handover corner, are completed naturally (by means of transports and moving hardware) or with an extraordinarily evolved parking robot, as is already in use.

Based on the meta- analysis for the reduction in required parking spots by 2033 there will be a requirement for $41 \%$ less parking spots. Despite these weights that expands opening rates, the parking structure has a few favourable circumstances over road and surface spaces that must be represented. Garage spaces can easily access electric charging stations, vehicle services, and different services that will be significant with shared, electric, autonomous vehicles. Moreover, vacancy may decrease as curb-side spaces are re purposed for other open uses, and parking garages are handily redeveloped into other land employments. 


\section{Conclusion}

The rebuilding and conceivable convergence of parking zones probably won't happen all over. It will essentially be confined to territories which are particularly appealing goals, and where costs for building the necessary parking areas, and along these lines additionally the engaging quality of space saving arrangements, are especially high (the significant expense and shortage of land coming about in multi-level arrangements). The extent to which the expenses of parking may change over the span of autonomous driving can't be evaluated. By building the special parking structures for autonomous vehicles, parking the vehicles on the streets and the parking costs in the streets of business districts can be avoided.

\section{References}

[1] IEEE. Look Ma, No Hands! IEEE Advancing Technology for Humanity News Releases, 2012. http://www.ieee.org/about/news/2012/5september_2 2012.html

[2] Litman, T. Autonomous Vehicle Implementation Predictions: Implications for Transport Planning, Victoria Transport Policy Institute, 2015. http://www.vtpi.org/avip.pdf

[3] Hoyt, Homer. Recent distortions of the classical models of urban structure. Land economics, 1964, 40(2): 199-212.

[4] United States Department of Agriculture: Economic Research Service. Summary Table 1 -Major Land Uses. 31 Jan. 2017, https://www.ers.usda.gov/data-products/major-land-uses/. Accessed 26 Jul. 2017.

[5] Lecraw, C. S., Smith, W. S.. Zoning Applied to Parking. Eno Foundation for Highway Traffic Control, 1947.

[6] Jakle, J. A., Sculle, K. A.. Lots of parking: Land use in a car culture. University of Virginia Press, 2004.

[7] Shoup, D. C.. The high cost of free parking. Chicago: Planners Press, 2005, 206.

[8] Mulley, C., Ison, S.. Transport and Sustainability. Parking: Issues and Policies. United Kingdom: Emerald Publishing, 2014, 5.

[9] Shoup, D.. Free Parking or Free Market. Unbound Magazine, Cato Institute. Washington, DC, 2011. https://www.cato-unbound.org/2011/04/04/donald-shoup/free-parking-or-ree-markets

[10] Ferguson, E.. Zoning for parking as policy process: A historical review. Transport Reviews, 2004, 24(2): 177-194.

[11] Chester, M., Fraser, A., Matute, J., Flower, C., Pendyala, R.. Parking infrastructure: A constraint on or opportunity for urban redevelopment? A study of Los Angeles County parking supply and growth. Journal of the American Planning Association, 2015, 81(4): 268-286. http://dx.doi.ore/10.1080/01944363.2015.1092879

[12] Maunsell. Realising the benefits of autonomous vehicles in Australia, Accenture, 2014.

13] Litman. Autonomous Vehicle Implementation Predictions: Implications for Transport Planning, Victoria Transport Policy Institute, 2014.

[14] Enoch. How a rapid modal convergence into a universal automated taxi service could be the future for local passenger transport, Technology Analysis \& Strategic Management, 2015, 27(8): 910-924.

[15] Skinner, R., N. Bidwell. Making Better Places: Autonomous vehicles and future opportunities, WSP, Parsons Brinckerho, 2016.

[16] Shi, L., P. Prevedouros. Autonomous and Connected Cars: HCM Estimates for Freeways with Various Market Penetration Rates, Transportation Research Procedia, 2016, 15: 389-402.

[17] K. Yang. Isolated intersection control for various levels of vehicle technology: Conventional, connected, and automated vehicles, Transportation Research Part C: Emerging Technologies, 2016.

[18] Bertoncello, Wee. Ten ways autonomous driving could redefine the automotive world, Article, McKinsey \& Company, 2015.

[19] Fagnant, D. J., K. M. Kockelman, P. Bansal. Operations of Shared Autonomous Vehicle Fleet for Austin, Texas, Market, Transportation Research Record: Journal of the Transportation Research Board, 2015, 2536: 8-106.

[20] Chester, M., Horvath, A., \& Madanat, 5.. Parking infrastructure: energy, emissions, and automobile life-cycle environmental accounting. Environmental Research Letters, 2010, 5(3): 034001. 